\title{
Efficiency enhancement of solar PV powered micro-integrated high frequency isolated vehicle battery charging converter
}

\author{
Jawahar $\mathbf{M}^{\mathbf{1}}$, Jayasankar $\mathbf{V}^{\mathbf{2}}$, Karthik Kumar $\mathbf{K}^{\mathbf{3}}$, Edward Rajan $\mathbf{S}^{\mathbf{4}}$ \\ 1,3,4 Department of Electrical and Electronics Engineering, Mepco Schlenk Engineering College, India \\ ${ }^{2}$ SoEC, Vel Tech Rangarajan Dr.Sagunthala R\&D Institute of Science and Technology, India
}

\begin{tabular}{l} 
Article Info \\
\hline Article history: \\
Received Jul 1, 2018 \\
Revised Nov 19, 2018 \\
Accepted Feb 20, 2019 \\
\hline Keywords: \\
Digital control scheme \\
Micro-integrated package \\
On-board battery charger \\
Solar PV systems \\
Zero Voltage Transition (ZVT)
\end{tabular}

\begin{abstract}
This Paper proposes a method to improve the efficiency of charging the battery used in autonomous electric vehicle powered by foldable roofmounted solar photovoltaic (PV) generation system. The conventional vehicle battery charging application from solar PV consists of a boost converter in the frontend followed by a full bridge converter with discrete switches. Here an attempt is made on the total scheme with a micro integrated package to have better conversion efficiency with high power density. The total system is controlled digitally incorporating zero voltage transition (ZVT) in the full bridge conversion. A typical specification with a power level of 300-400 W was targeted and achieved.
\end{abstract}

Copyright (C) 2019 Institute of Advanced Engineering and Science. All rights reserved.

\section{Corresponding Author:}

Jawahar M,

Department of Electrical and Electronics Engineering,

Mepco Schlenk Engineering College, Sivakasi,

Mepco Engineering College (PO), Mepco Nagar, Sivakasi-626 005, India.

Email: jawahar.m@mepcoeng.ac.in

\section{INTRODUCTION}

In recent times of rapidly growing power demand and very slowly improving supplying ability, there are more chances of power outage presently and zero energy production from fossil fuels in future. Also, most of the remote areas are not connected to the grid and they do not have power supply. These areas can generate power on their own using renewable resources such as solar PV energy systems. This solar PV, if mounted on vehicles it can produce its energy indigenously and provided storage systems enable its usage at times of demand. The efficiency of the solar PV energy system exclusively depends on the PV panels, converters and the Maximum Power Point Tracking system. The efficiency of a single PV cell is very low[2].

The efficiency of hard switching converters is low. So they can be replaced by the soft switching converters that have very less losses and high efficiency. Use of good and efficient MPPT algorithm also improves the system efficiency [1]. It is possible to achieve the maximum efficiency with a single stage conversion. Yet, a two stage conversion is implemented in this scheme in order to provide the isolation between the source and the load. Hence, a galvanic isolation by means of high frequency transformer is provided and the entire scheme is now managed using analog based control systems. The present scenario in DC-DC Converters is to switch at high frequencies, in the range of a few $\mathrm{MHz}$, with a scope to achieve high power densities [1].

Boost Converter is implemented in the scheme in order to boost the voltage from the solar PV energy systems. The boost converter with the duty ratio, $\mathrm{D}>0.5$, it provides the desired voltage, targeted for the application [3]. Full bridge converter is used as a second stage converter from DC to AC with a fixed duty ratio of 0.5 , such that it converts the DC to AC with minimized losses through ZVT scheme implemented in Phase Shifted FBC operation modes [4]. 
High frequency transformer which is used for galvanic isolation is provided with higher turns on the secondary in order to mitigate the considerable losses that occurs during switching in the full bridge converter though ZVT scheme is implemented [5]. The analog IC used here for controlling the PWM pulses to the MOSFET's inside the package is UC3526 [6] for boost operation and UC3872[6] for PSFBC with ZVT scheme operation. The electric vehicle used for the study uses $72 \mathrm{~V}$ lead acid accumulators which consist of $12 \mathrm{~V}$ battery each connected in series of 6 numbers to power the vehicle during acceleration [1].

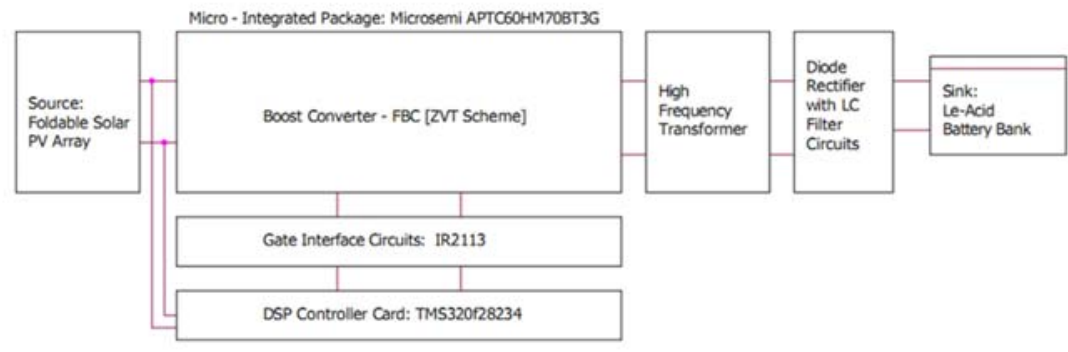

Figure 1. Block diagram of proposed scheme

\section{FOLDABLE SOLAR PV ENERGY SYSTEMS}

Solar PV energy systems are used to convert the trapped solar light into electricity. PV cells are the layers undergo a process of addition of impurities, usually called doping to materialize a P-N junction. A very thin grid (metallic) is planted on the top of the PV cell which faces the sun. As the light is incident on the surface of the cell, charge carriers are generated, which originates an electric current when the cell becomes a part of a loop or is connected to a load [2]. As the energy of the incident photon becomes sufficient to break the covalent bond and detach the electrons of the semiconductor, charge carriers are generated. Photons that have lower energies than the energy gap of PV cell are not of any use and they help generating no voltage. Whereas Photons that have energy surpassing the band gap can produce electricity, but the energy associated with the band gap is only made use of. The remaining energy will be dissipated in the form of heat.

The single diode model of a PV cell is shown in Figure 2. It includes a current source, a diode, in parallel connected to the current source which represents the photocurrent, a series resistance Rse and a parallel resistance Rsh.

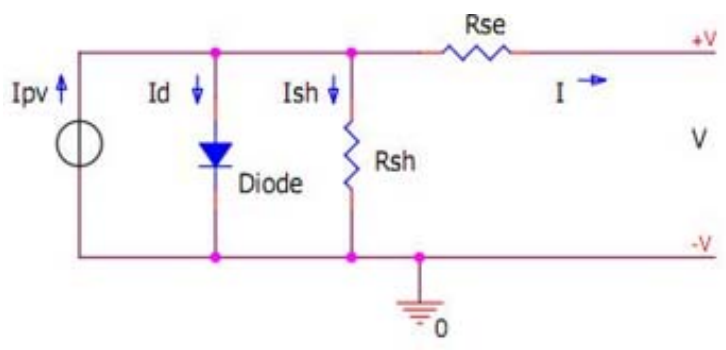

Figure 2. Equivalent circuit of PV cell

$$
\begin{aligned}
& I=I_{P V}-I_{d}-I_{s h} \\
& I=I_{P V}-I_{d}\left[\frac{e\left(V+I R_{S e}\right)}{m K T}-1\right]-I_{s h}
\end{aligned}
$$

Where,

I $\quad=$ Output current of PV panel (A)

IPV $\quad=$ Current generated by the PV cell $(\mathrm{A})$

Id $=$ Current through diode $(\mathrm{A})$

Int J Pow Elec \& Dri Syst, Vol. 10, No. 2, June 2019 : 953 - 960 


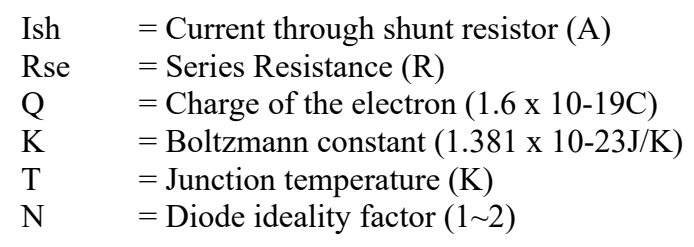

The power of the $\mathrm{PV}$ cell is $\mathrm{P}=\mathrm{VI}$

Where,

$\mathrm{V} \quad=$ Output voltage of the PV panel

I $\quad=$ Output current of the PV panel

Table 1. Requirement specification of the PV panel

\begin{tabular}{cc}
\hline Parameters & Values \\
\hline $\mathrm{R}_{\mathrm{s}}$ & $0.62 \Omega$ \\
$\mathrm{I}_{\mathrm{sc}}$ & $6.98 \mathrm{~A}$ \\
$\mathrm{R}_{\mathrm{sh}}$ & $250.57 \Omega$ \\
$\mathrm{V}_{\mathrm{oc}}$ & $49.87 \mathrm{~V}$ \\
$\mathrm{~N}$ & 1.3 \\
\hline
\end{tabular}

Table 1 shows the parameters for the Solar PV panel. From the specifications the experimental operation has been done. The power rating and the maximum voltage of the solar PV panel has shown in the Table 2. Using the PV cell power (3), the rating of the module is proposed. Table 2 demonstrates the MPPT rating of the PV panel. Here, for tracking maximum power from the PV panel, the perturb and observe method is implemented.

\begin{tabular}{cc} 
Table 2. MPPT ratings of the PV panel \\
\hline Parameters & Values \\
\hline $\mathrm{P}_{\max }$ & $372 \mathrm{~W}$ \\
$\mathrm{I}_{\operatorname{mpp}}$ & $6.55 \mathrm{~A}$ \\
$\mathrm{~V}_{\operatorname{mpp}}$ & $41.58 \mathrm{~V}$ \\
\hline
\end{tabular}

\section{PROPOSED POWER CIRCUIT DESIGN}

\subsection{Proposed Solar PV Based micro-integrated converter}

Closing the switch which is usually an electronic device (MOSFET) that operates in two states: When the switch is ON for a time duration DT (D is the duty ratio), the switch conducts the inductor current and the diode becomes reverse biased. This results in a positive voltage across the inductor. The virtues of lossless transitions using Zero Voltage Switching techniques have already been traditional in power management applications. Effects of the parasitic circuit elements are used advantageously to assist the resonant transitions as opposed to being dissipative snubbed. This resonant tank functions to position zero voltage across the switching device prior to turn-on, eliminating any power loss due to the simultaneous overlap of switch current and voltage at each transition. High frequency converters operating from high voltage input sources stand to gain significant improvements in efficiency with this procedure.

Rather than driving both of the diagonal full bridge switches together, a purposeful delay will be introduced between their turn-on commands with the Phase Shifted approach. This delay will be adjusted by the voltage loop of the control circuit, and in effect results as a phase shift between the two drive signals. The effective duty ratio is exclusively to this Phase Shifted technique [4], two of the switches in series with the transformer can be $\mathrm{ON}$, yet the applied voltage to the transformer is zero. These are not diagonal switches of the full bridge converter, but either the two upper or two lower switches. In this mode the transformer primary is essentially short circuited and clamped to the respective input rail. Primary current is maintained at its previous state since there is no voltage available for reset to take place. This dead band fills the void between the resonant transitions and power transfer modes of the conversion cycle. Switches can be held in this state for a certain period of time which corresponds to the required off time for that particular switching cycle. 


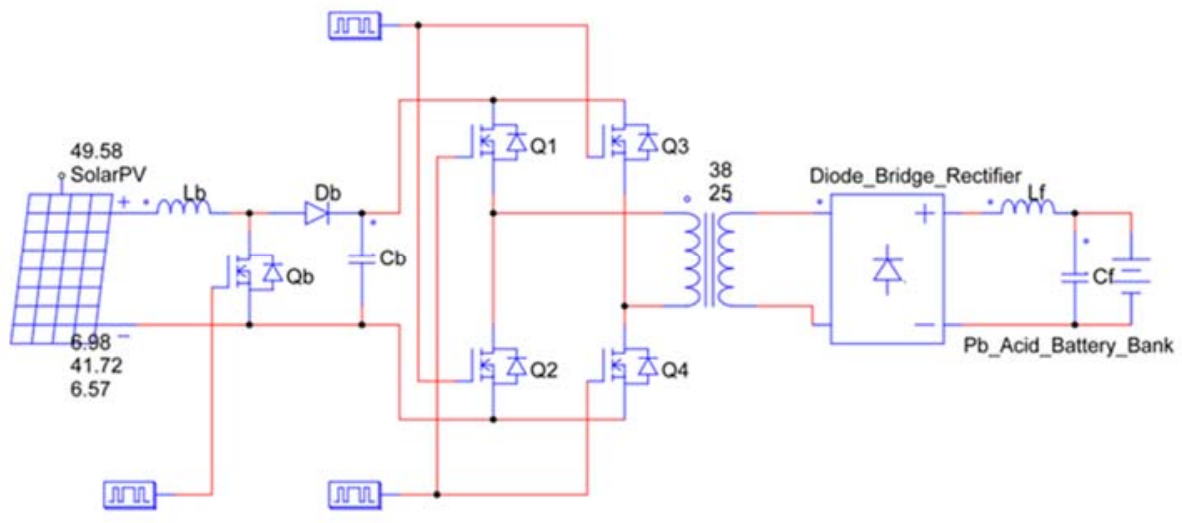

Figure 3. Open loop analysis of the proposed system

Table 3. Design Parameters

\begin{tabular}{lc}
\hline \multicolumn{1}{c}{ Parameters } & Values \\
\hline Input Voltage & $44.6 \mathrm{~V}$ \\
Output DC Voltage & $72 \mathrm{~V}$ \\
Rated Power & $350 \mathrm{~W}$ \\
Swiching Frequency & $50 \mathrm{kHz}, 100 \mathrm{kHz}$ \\
Boost Inductor $\left(\mathrm{L}_{\mathrm{b}}\right)$ & $0.46 \mathrm{mH}$ \\
Boost Capacitor $\left(\mathrm{C}_{\mathrm{b}}\right)$ & $6.8 \mu \mathrm{F}$ \\
Transformation Ratio & 1 \\
Inductive filter $\left(\mathrm{L}_{\mathrm{f}}\right)$ & $1 \mathrm{mH}$ \\
Capacitive filter $\left(\mathrm{C}_{\mathrm{f}}\right)$ & $100 \mu \mathrm{F}$ \\
Battery & $12 \mathrm{~V}, 7 \mathrm{Ah}$ \\
\hline
\end{tabular}

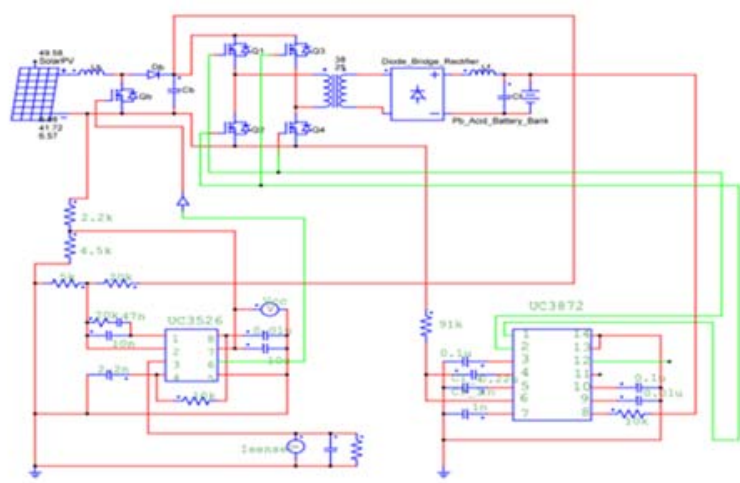

Figure 4. Closed loop analysis of the proposed system

These are not diagonal switches of the full bridge converter, but either the two upper or two lower switches. In this mode the transformer primary is essentially short circuited and clamped to the respective input rail. Primary current is maintained at its previous state since there is no voltage available for reset to take place. This dead band fills the void between the resonant transitions and power transfer modes of the conversion cycle. Switches can be held in this state for a certain period of time which corresponds to the required off time for that particular switching cycle.

The open loop simulation analysis of the proposed scheme is shown in Figure 3 and closed loop simulation analysis shown in Figure 4 is performed using the analog IC's-UC3526 and UC3872. Based on the design parameter in Table 3, the closed loop analysis implemented using the analog IC, which provides better accuracy for the converter scheme is to operate at desired gating pulse. The switching frequency 50 
$\mathrm{kHz}$ is used at boost stage and $100 \mathrm{kHz}$ is used at phase shifted conversion stage to improve the efficiency. Hence, the open loop has given an efficiency of $83.52 \%$ whereas with combined closed loop converter testing, the efficiency has improved to $87.34 \%$.

\section{RESULTS AND PERFORMANCE ANALYSIS}

\subsection{Need for packaged switches for efficiency improvements}

The switches, modelled as package (Microsemi package - APTC60HM7BT3G) helps to improve the power densities as the volume per area loss are reduced. The packaged switches aids in the compact design of the power boards, hence the space requirement and thermal design constraints are comparatively less than the conventional design.

\subsection{Closed loop performance analysis of the proposed system}

In order to improve the accuracy and make adapt the system to dynamic conditions on varying solar power and load requirements, the closed-loop control of the converter is done using UC3526[5] and UC3872[6] IC's for the Boost and PSFBC with ZVT scheme implemented. The functionality of the analog IC's is modeled as a physical component for simulation. The Combined Boost and the PSFBC converter simulation

is

Figure 4 and Figure 5. This combined converter will be replaced with Microsemi packageAPTC60HM7BT3G, instead of the discrete switches in order to improve the efficiency and power density while realizing as the prototype. The simulation is developed in POWER SIM which is an electronic circuit simulation software package.

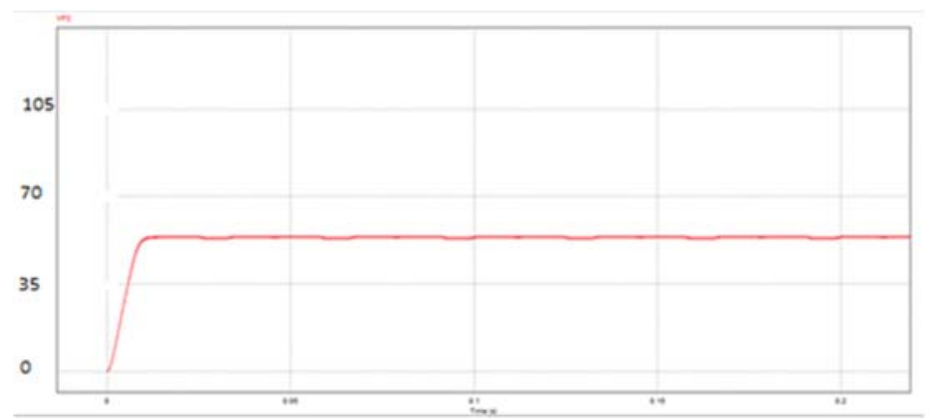

(a)

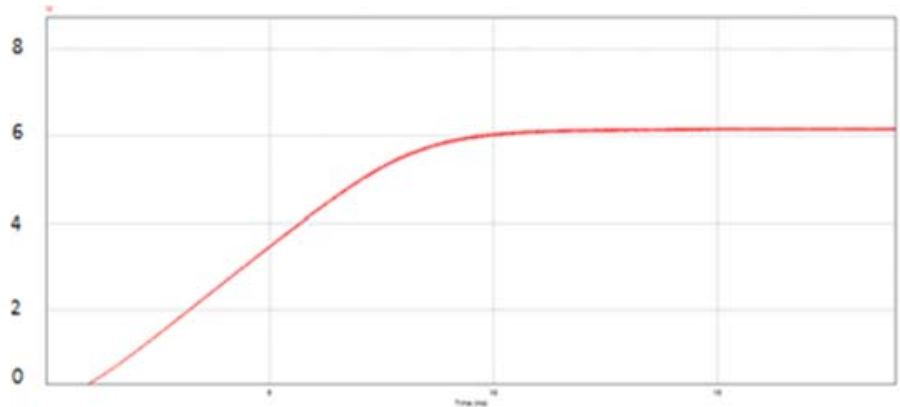

(b)

Figure 5. (a) Output voltage waveform (b) Output current waveform

To evaluate the performance of the proposed system, the results obtained from digital control scheme is compared with the analog IC scheme. The comparison of the output voltage waveform clearly reveals that for closed loop analysis using the analog control scheme gives a maximum efficiency of $87.34 \%$. Whereas the digital control scheme improves the efficiency of conversion by increasing the accuracy which results around $90.78 \%$ as shown in Table 4 and Table 5 .

Table 4. Performance investigation of digitally controlled open loop proposed system

Efficiency enhancement of solar PV powered micro-integrated high frequency isolated ... (Jawahar M) 


\begin{tabular}{cccccccc}
\hline $\begin{array}{c}\text { Input } \\
\text { Voltage } \\
(\mathrm{V})\end{array}$ & $\begin{array}{c}\text { Input } \\
\text { Current } \\
(\mathrm{A})\end{array}$ & $\begin{array}{c}\text { Input } \\
\text { Power } \\
(\mathrm{W})\end{array}$ & $\begin{array}{c}\text { Output } \\
\text { Voltage } \\
(\mathrm{V})\end{array}$ & $\begin{array}{c}\text { Output } \\
\text { Current } \\
(\mathrm{A})\end{array}$ & $\begin{array}{c}\text { Output } \\
\text { Power } \\
(\mathrm{W})\end{array}$ & $\begin{array}{c}\text { Duty } \\
\text { Ratio } \\
(\mathrm{D})\end{array}$ & $\begin{array}{c}\text { Efficiency } \\
(\%)\end{array}$ \\
\hline 44.6 & 8.67 & 386.6 & 52.70 & 5.76 & 303.57 & 0.153 & 78.56 \\
44.6 & 8.67 & 386.6 & 57.41 & 5.41 & 310.05 & 0.206 & 80.21 \\
44.6 & 8.67 & 386.6 & 75.03 & 4.72 & 315.15 & 0.239 & 81.52 \\
\hline
\end{tabular}

Table 5. Performance investigation of digitally controlled closed loop proposed system

\begin{tabular}{cccccccc}
\hline $\begin{array}{c}\text { Input } \\
\text { Voltage } \\
(\mathrm{V})\end{array}$ & $\begin{array}{c}\text { Input } \\
\text { Current } \\
(\mathrm{A})\end{array}$ & $\begin{array}{c}\text { Input } \\
\text { Power } \\
(\mathrm{W})\end{array}$ & $\begin{array}{c}\text { Output } \\
\text { Voltage } \\
(\mathrm{V})\end{array}$ & $\begin{array}{c}\text { Output } \\
\text { Current } \\
(\mathrm{A})\end{array}$ & $\begin{array}{c}\text { Output } \\
\text { Power } \\
(\mathrm{W})\end{array}$ & $\begin{array}{c}\text { Duty } \\
\text { Ratio } \\
(\mathrm{D})\end{array}$ & $\begin{array}{c}\text { Efficiency } \\
(\%)\end{array}$ \\
\hline 44.6 & 8.67 & 386.6 & 66.71 & 5.11 & 338.66 & 0.153 & 87.16 \\
44.6 & 8.67 & 386.6 & 71.49 & 4.77 & 341.01 & 0.206 & 88.21 \\
44.6 & 8.67 & 386.6 & 77.64 & 4.52 & 350.95 & 0.239 & 90.78 \\
\hline
\end{tabular}

The ZVT scheme implemented in the proposed phase shifted full bridge converter is shown in the Figure 6. From the graph, It is evident that the scheme helps in the minimization of the power loss happened during the conversion process with an improved efficiency compared to conventional switching strategy. From Figure 7, the galvanic isolated output of the converter along the non-synchronized rectifier is depicted and hence it reveals with minimized distortion that aided in the reduction of the filter requirements. The Micro-semi package based converter hardware setup is shown in the Figure 8.

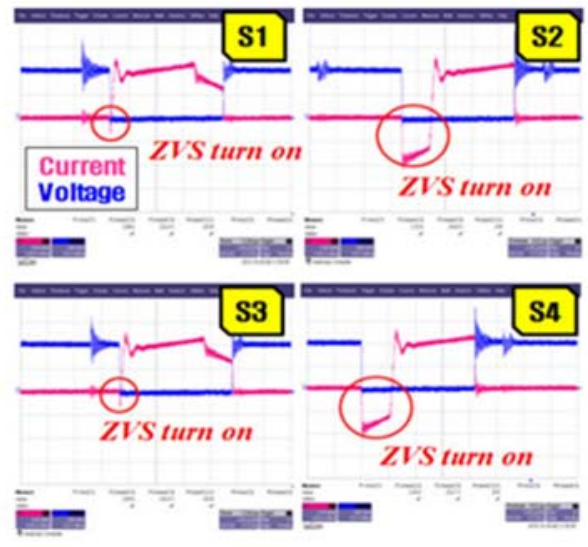

(a)

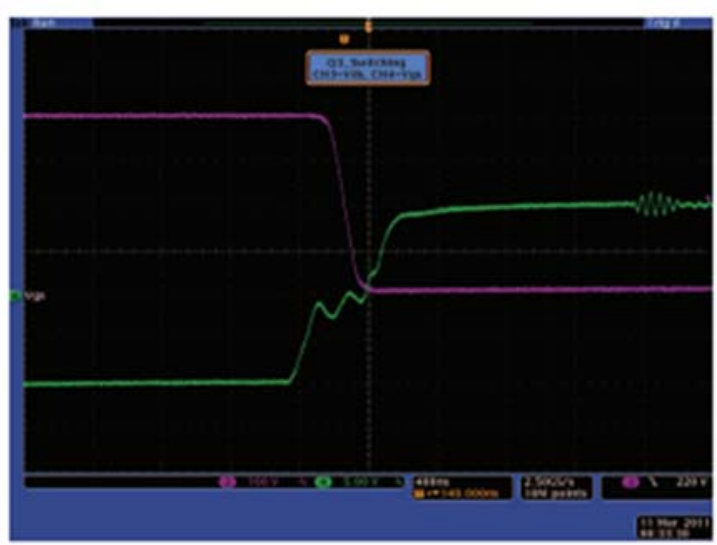

(b)

Figure 6. (a) ZVT on and off characterisitics (b) Left and right leg transisiton in PSFBC

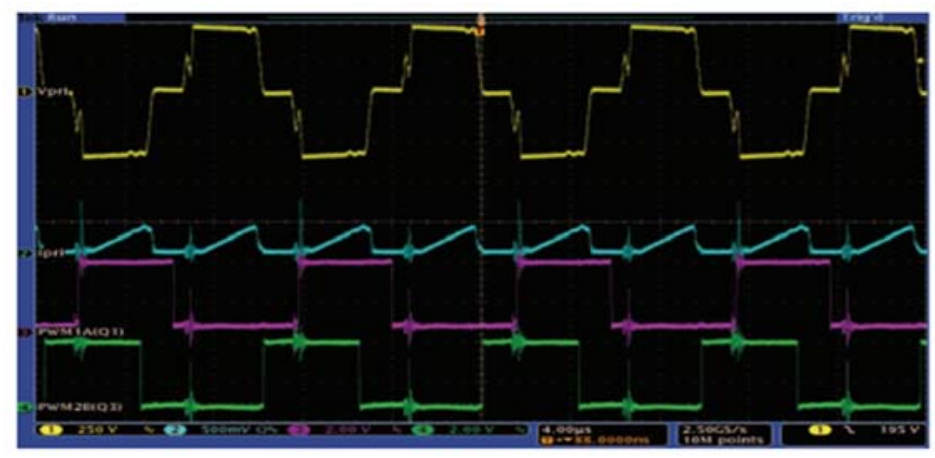

Figure 7. Output voltage of the transformer and rectifier of the proposed scheme 

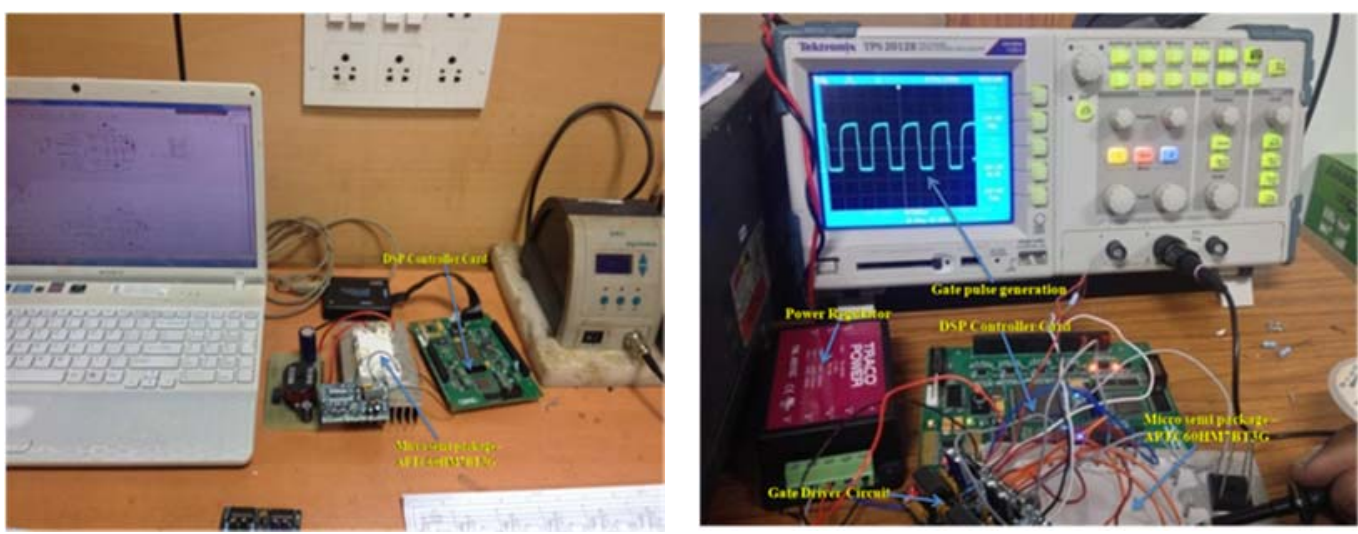

Figure 8. Hardware setup of the digitally controlled proposed system

\section{CONCLUSION}

In this paper, a PV interface based micro integrated packaged converter concept for electric vehicle battery charging has been proposed. Utilizing the micro integrated package, instead the discrete switches, aids in the improvement of the efficiency of the solar power conversion for electric vehicle battery charging, hence the power density can be improved by operating the converter in high frequency. With further improvements in providing the effective MPPT for solar conversions and digitized control scheme for the proposed model would reap a further more increase in efficiency. Neglecting the undesirable losses in the converter is a key solution for the enhancement of efficiency and effective power density could be achieved simultaneously with this proposed approach.

Based on analysis, the control parameters have been designed to guarantee detection time and maintain the system efficiency. A prototype converter is under implementation to verify the simulation results implemented and its experimental results have verified the feasibility of the converter. This study should be helpful to implement high efficiency and long lifetime guaranteed PV interface converters with minimized losses. In addition, the experimental results have showed that the proposed converter package aids battery charging with low EMI and EMC problems during power conversions.

\section{ACKNOWLEDGEMENTS}

The authors express their gratitude to Dr. S.Arivazhagan, Principal, Mepco Schlenk Engineering College, Sivakasi, for providing the state of the art laboratory facilities in the Department of Electrical and Electronics Engineering and also Shri. V.Chandrasekar, Scientist - F/Associate Director, Power Electronics Group, Centre for Development of Advanced Computing, Thiruvananthapuram, Govt. of India, for his sustenance from the commencement of the research work till the completion.

\section{REFERENCES}

[1] Ching-Ming Lai, Yu-Huei Cheng, Ming-Hua Hsieh, Yuan Chih Lin, "Development of a Bidirectional DC/DC Converter with Dual-Battery Energy Storage for Hybrid Electric Vehicle System," IEEE Trans. on Vehicular Technology, vol. 67, pp. 1036 - 52, 2018.

[2] Navid Shafiei, Martin Ordonez, Mohammed Ali Saket Tokaldani, Seyed Ali Arefifar, "PV Battery Charger Using an L3C Resonant Converter for Electric Vehicle Applications," IEEE Trans. on Transportation Electrification, vol. 4, pp. 108-121, 2018.

[3] Rouzbeh Reza Ahrabi, Hossein Ardi, Mahdi Elmi, Ali Ajami, "A Novel Step-up Multiinput DC-DC Converter for Electric Vehicle Application," IEEE Trans. on Power Electronics, vol. 32, pp. 3549-4561, 2017.

[4] A.S.Samosir, Taufiq, A.J.Shaafie, A.H.M.Yatim, "Simulation and Implementation of Interleaved Boost DC-DC Converter for Fuel Cell Application," International Journal of Power Electronics and Drives System, vol. 1, pp. 168-174, 2011.

[5] Nikhil Jain, Praveen K.Jain and Geza Joos, "A Zero Voltage Transition Boost Converter Employing a Soft Switching Auxiliay Circuit With Reduced Conduction Losses," in IEEE Transactions on Power Electronics, vol.19, no.1, January 2004.

[6] TI application note: Digitally Controlled HV Solar MPPT DC-DC Converter Using C2000 ${ }^{\mathrm{TM}}$ Piccolo $^{\mathrm{TM}}$ Microcontroller by Texas Instruments, USA, 2004. 


\section{BIOGRAPHIES OF AUTHORS}

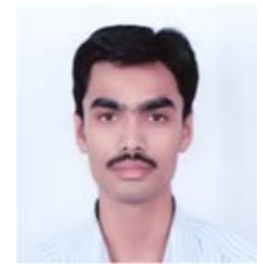

Jawahar M is an Assistant Professor in the Department of Electrical and Electronics Engineering, Mepco Schlenk Engineering College, Sivakasi, since June 2016. He holds BE (EEE) and ME (Power Electronics and Drives) from the Faculty of Electrical Engineering, Anna University, Chennai with a Gold Medal and a University Rank in 2012 and 2016 respectively. He has worked as an Associate Software Engineer at Accenture, India from 2012 - 14 and also interned at Electrical Services Group, IGCAR, Kalpakkam, Govt. of India and Power Electronics Group, C-DAC, Thiruvananthapuram, Govt. of India in 2011-12 and 2015-16 respectively. He is the recipient of research fellowship from the Indian Institute of Technology Delhi, New Delhi in 2017. He has authored and published 11 research articles in reputed international and national journals/conferences. He is the Life Member, ISTE and Member, IEEE, IAENG.

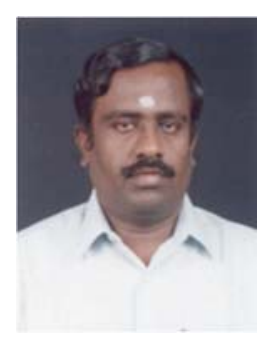

Jayasankar V is the Professor and Dean in the School of Electrical and Communication Engineering, Vel Tech Rangarajan Dr.Sagunthala R\&D Institute of Science and Technology, Avadi, Chennai, since July 2017. He holds BE (EEE) from Government College of Technology, Coimbatore in 1979 and ME (High Voltage Engineering) and $\mathrm{PhD}$ (Electrical Engineering) from the Faculty of Electrical Engineering, Anna University, Chennai in 1995 and 2011 respectively. He has served in various positions from November 1986 and retired as a Senior Professor and Head in the Department of Electrical and Electronics Engineering, Mepco Schlenk Engineering College, Sivakasi. Earlier, he was employed as an Assistant Engineer, TNEB for 7 years. He has authored and published finite articles in reputed international and national journals/conferences. He has successfully completed 4 sponsored research funded projects as Principal Investigator and as Co-Principal Investigator from IGCAR, NPOL, AICTE-RPS, RuTAG-IIT Madras. He is the Life Member, ISTE and IE (I).

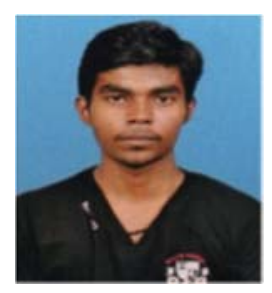

Karthik Kumar K is a PG scholar in the Department of Electrical and Electronics Engineering, Mepco Schlenk Engineering College, Sivakasi. He holds BE (EEE) from Mepco Schlenk Engineering College, Sivakasi in 2017. His research interest includes power electronics converters for electric vehicle application. He has published 2 research articles in an international conference / journals.

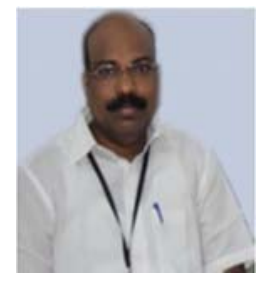

Edward Rajan S is a Senior Professor in the Department of Electrical and Electronics Engineering, Mepco Schlenk Engineering College, Sivakasi, since 1996. He holds BE (ICE) from Madurai Kamaraj University, Madurai in 1991 and ME (Electrical Engineering) from Jadavupur University, Kolkata in 1996 and $\mathrm{PhD}$ (Electrical Engineering) from the Faculty of Electrical Engineering, Madurai Kamaraj University, Madurai in 2006. He is recognized as an approved research supervisor for guiding Ph.D. by Anna University, Chennai. Presently, under his supervision, four scholars are pursuing their Ph.D. and seven scholars have completed their $\mathrm{Ph} . \mathrm{D}$ under Anna University, Chennai. He has published 47 research papers in the reputed International Journals. His main research interests include Renewable power generation, Power converters, Modeling \& Simulation of Instrumentation systems, Medical Image Processing and Bio-medical instrumentation. He is a Life Member in Indian Society for Technical Education and also a Fellow Member in The Institution of Engineers (India). 